\title{
Resilient optimal design of multi-family buildings in future climate scenarios
}

\author{
Matteo Bilardo ${ }^{1}$, Maria Ferrara ${ }^{1}$, and Enrico Fabrizio ${ }^{1, *}$ \\ ${ }^{1}$ Politecnico di Torino, DENERG, Corso Duca degli Abruzzi 24, 10129, Torino, Italy
}

\begin{abstract}
In Europe, the second recast of EPBD promotes long-term strategies to accelerate the path to nZEBs, fostering the cost-optimized building design already suggested in the EPBD first recast. Since the nZEB design is a complex optimization problem that is subjected to uncertainty in its boundary conditions (climate, technologies, market, ...), it is necessary to guarantee the resilience of the NZEB optimal design to possible variations of future scenarios, especially as regards the climate change. This work applies the new EdeSSOpt methodology (Energy Demand and Supply Simultaneous Optimization) developed by the Authors aiming at investigating the variation of the cost-optimized multi-family building design in different Italian future climate scenarios, therefore considering parameters related to the building envelope, energy systems and renewable energy sources. The method is implemented into the TRNSYS® (energy model), GenOpt (optimizer) and WeatherShift ${ }^{\circ}$ (future climate scenario generator) tools. The resulting cost-optimal solutions in future scenarios are related to a lower global cost and a decreased total primary energy consumption. Beyond the future trends of such performance indexes, the fact that most of technical solutions associated with the optimal solutions have not changed with the studied climate scenarios, indicates a certain resilience of the optimal design variables facing climate change.
\end{abstract}

\section{Introduction}

Being the main responsible for energy consumption in Europe, the building sector has great potential for optimization and improvement in energy and cost-related terms [1]. $40 \%$ of European primary energy consumption involves residential and non-residential buildings [2]. This fact led the European Commission to take action on the matter with the Energy Performance of Building Directive (EPDB) and its recasts, promoting some guidelines on the energy efficient design and innovation of buildings with the aim of defining a roadmap towards the decarbonization of the European building stock, achieving the nZEB (nearly Zero Energy Building) objective [3]. In this context, the first EPBD recast foresees the implementation of innovative energy efficiency measures in order to reduce the energy needs of buildings as well as their maintenance costs over the short, medium and long term [3].

Furthermore, the 2018 EPBD recast put forward that energy efficiency measures should not just be focused on the building envelope components, but also consider technical systems, taking into account both the energy consumption side and the economic aspect of such measures. In order to propose a model of sustainable development, the economic assessment must be taken into account, so as to propose possible tangible solutions that can be implemented [4].

Many of the possible technologies that emerged in recent years to achieve the nZEB target, while being energy-efficient, are not as promising on the economic side. To promote the development of economically feasible solutions, the EPDB has introduced the costoptimal methodology, a framework adopted by both the Member States and the scientific community that aims to find cost-effective design solutions for energy saving [5, 6].

The cost-optimal methodology requires comparing possible combinations of energy efficiency measures to determine which of them has the lower economic impact over the building economic lifecycle. The solution to this problem is nothing other than the search of the minimum of an objective function, the so-called Global Cost function, therefore constituting a complex optimization problem.

In this perspective, such optimization process acquires significant importance in the preliminary phase of designing new buildings, being able to provide a set of energy-performing solutions with the highest level of feasibility $[7,8]$. Furthermore, an ever-increasing amount of optimization variables reveals the need for appropriate simulation-based optimization strategies that are able to search within a great number of design solutions of which the performance needs to be evaluated in detail.

Within the so-defined optimization problem, one aspect to take into consideration is certainly the relationship between the many optimization variables and the boundary conditions, such as climate data, the available technologies, the market context, etc., which are subject to uncertain future evolution [9]. Considering

Corresponding author: enrico.fabrizio@polito.it 
different future scenarios may lead to significant variations in the optimal design solutions, but this approach is not included in the cost-optimal framework for nZEB design proposed by the EPDB recast, which only proposes a sensitivity analysis based on financial data. However, recent scientific research confirmed that future energy consumption will be strongly influenced by climate change $[10,11]$. This problem has already been addressed by many studies focused on the prediction of climate models, based on the Intergovernmental Panel of Climate Change predictions [12]. A first application of climate scenarios within the cost-optimal methodology can be found in [13] for a simple single-family building, but it is an open issue that has to be addressed for more complex case-study buildings in different contexts.

The integration of the cost-optimal methodology with future climate scenarios results in a very challenging topic in line with the last provisions of the second EPBD recast, because it aims to find economically sustainable solutions that take into account the weather evolution in the future.

By adopting this research methodology, more reliable solutions can be achieved to guarantee a building design that is resilient to climatic variations, leading to more effective long-term strategies towards the nZEB objective.

\subsection{Aim of the present study}

This study aims to investigate the effects of global cost optimization performed on a real case study subjected to different future climate scenarios, for the period 20262045. The analysis contained in this paper made it possible to compare the results obtained with those produced by the actual climate situation (reference weather condition). The optimization process was developed through a new EDeSSopt (Energy Demand and Supply Simultaneous Optimization) framework [14] able to simultaneously optimize parameters related to the building envelope, energy supply systems and renewable sources. The purpose of this investigation is to explore the influence of future climate scenario in the relationship between energy demand and supply in a simulation-based optimization framework. In particular, there are two primary objectives of this study:

1. To define energy efficiency measures and future climate scenarios for the design optimization of a multifamily building in the Italian context;

2. To study the resilience of the optimal solution with respect to changes in climatic conditions

Several future climate scenarios in this respect have been applied to the same case study to assess the energy impact on the building.

In this work, the dynamic energy behaviour of the building was studied with TRNSYS ${ }$ while the GenOpt ${ }^{\circledR}$ software was used to perform the optimization task.

\begin{tabular}{|ll|}
\hline Nomenclature & \\
ResR & Thickness of insulation in the roof \\
Res2 & Thickness of insulation in the first floor \\
\hline
\end{tabular}

\begin{tabular}{|c|c|}
\hline $\mathrm{ResO}-\mathrm{N}$ & $\begin{array}{l}\text { Thickness of insulation in the wall } \\
\text { facing North }\end{array}$ \\
\hline ResO-EWS & $\begin{array}{l}\text { Thickness of insulation in the walls } \\
\text { facing East/West/South }\end{array}$ \\
\hline WTN & North windows type \\
\hline WTS & South windows type \\
\hline WTEW & East/West windows type \\
\hline WFactor & Windows area increasing factor \\
\hline T-Gen & Generator type \\
\hline T-Ter & Terminals type \\
\hline T-Aux & Auxiliary heater type \\
\hline T-PV & PV type \\
\hline Perc-PV & Percentage of PV installed \\
\hline Perc-TH & Percentage of solar thermal installed \\
\hline Dim-WS & Water storage dimension \\
\hline
\end{tabular}

\section{Methodology}

\subsection{Case study building and optimization variables}

The case study building is a 6-floors residential complex located in Milan, Italy. For the purpose of this study, a portion of the complex including 35 residential apartments for a total heated surface of about $2460 \mathrm{~m}^{2}$ was considered. The opaque envelope of the building is made of reinforced concrete and bricks with an insulation layer on the outside side. The global transmittance of the wall is equal to $0.26 \mathrm{~W} / \mathrm{m}^{2} \mathrm{~K}$. The glazed elements consist of double glazing with a metal frame and their total transmittance value is $1.45 \mathrm{~W} / \mathrm{m}^{2} \mathrm{~K}$.

In the study presented in this paper, the optimization variables adopted concern the building envelope, technical systems and renewable energy technologies. Different configurations of these types of variables were simulated to minimize the global cost.

4 optimization variables were taken into account for the opaque building envelope: the thickness of the insulation in the roof (ResR), in the external walls facing North (ResO-N), in the external walls towards other orientations (ResO-EWS) and in the floor of the first floor (Res2). For the transparent components, three variables were considered to describe the orientation of the windows: North (WTN), South (WTS) or East/West (WTEW). Each of these variables can be represented by 5 types of selected windows: three types with double glazing and two types with triple glazing (Table A.2 in the Appendix). An additional variable (WFactor) considers a possible variation in the transparent surfaces of $\pm 20 \%$ compared to the building design conditions.

Regarding the technical system, the optimization variables include the choice of the heat generator ( $\mathrm{T}$ Gen), the heating terminals (T-Ter), the auxiliary heaters (T-Aux), the photovoltaic panels (T-PV), the size of the thermal storage (Dim-WS) and the percentage of renewable resources installed in the building (Perc-PV and Perc-TH). More details on optimization variables are collected in Table A.3 in the Appendix.

The so-defined optimization problem has therefore a 15-dimensional design space composed of $3 \cdot 10^{13}$ possible design solutions, a value that underlines the importance of implementing an optimization algorithm, 
such as the Particle Swarm Optimization (PSO), in order to minimize the objective function. The PSO algorithm is a heuristic search method that optimizes a problem using a population of candidate solutions. By studying the displacement of populations in the solutions space, this algorithm tries to converge towards a local minimum implementing specific logic inspired by swarm movement. This algorithm has been proved to be effective in cost-optimal studies [15].

\subsection{The global cost function}

The technical-economic analysis is the main objective of this optimization study, where the objective function is the global cost. The objective function, reported in equation (1), takes into account both the initial investment costs, as well as the operational and maintenance costs. The purpose of cost-optimal analysis is to minimize the overall cost, calculated according to the European Standard EN15459 [16]. In the global cost function, $C I$ represents the initial investment cost of the system, $C_{a, j}(i)$ the cost related to the correct operation and maintenance of the component $j$ during the year $i$ and $R_{d}(i)$ is discount rate for the year $i$ (set at $4.5 \%$ ). The calculation period $\mathrm{T}$ has been set equal to 30 years. Finally, the term $V_{f}(j)$ represents the economic value of each component $j$ at the end of the calculation period.

$$
C_{G}(T)=C I+\sum_{j}\left[\sum_{i=1}\left(C_{a, j}(i) * R_{d}(i)\right)-V_{f, r}(j)\right]
$$

For each component $j$ that are the optimization variables presented above, specific cost functions were assessed to evaluate the related investment and O\&M costs. For more details on cost functions, refer to tables A.1, A.2 and A.3 in the Appendix.

In addition to the global-cost function, the simulation software also evaluates other secondary functions useful for understanding the energetic behaviour of the simulated scenario. For instance, the total primary energy of the building $E P_{\text {tot }}$ is evaluated, considering the conversion factor proposed by the Italian standards [17].

\subsection{The EDeSSOpt methodology}

The optimization process of the cost-optimal function has been developed through the coupling of TRNSYS $\AA$, a dynamic energy simulation software, with the GenOpt ${ }^{\circledR}$ optimization program, in a so-called simulation-based optimization approach. The innovative methodology proposed in solving this problem consists in a simultaneous optimization of the energy demand and supply (EDeSSOpt) of the case study building. The optimization procedure is therefore not separated in two or more phases as in more traditional optimization processes, where the global cost is first optimized for the energy demand side and then from the supply point of view [18]. The EDeSSOpt methodology allows to evaluate the economic impact that an optimization variable has on a given energy production system. For example, with this approach it is possible to evaluate how convenient it is to modify a building envelope parameter rather than a heat generator.
The optimization process is initialized by GenOpt, which assigns a random value to the input variables. These optimization variables, together with the boundary conditions of the problem (case study geometry and climate) are transmitted to TRNSYS which simulates the energy behaviour of the building in those conditions, calculating the value of the global cost function. Once the energy simulation is terminated, GenOpt evaluates the result of the objective function and, based on PSO algorithm, modifies the values of the optimization variables that are used to launch a new simulation in TRNSYS. This iterative process is repeated until the termination criterion, set to 100 generations, is reached.

\subsection{Future climate scenarios}

The Milan-IWEC weather file was used as a reference scenario, denoted by RW. Starting from it, according to the climate change forecast foreseen by the IPCC Fifth Assesment, future weather files were generated using WeatherShift ${ }^{\circledR}$ software tool [19].

Future weather projections were generated using the morphing method implemented in the software [20]. The generated scenarios take into account two climate factors. The Representative Concentration Pathways (RCP) is a factor used to determine future scenarios by assuming a trend in greenhouse gas emissions. Two RCP scenarios were considered: the 4.5-moderately aggressive mitigation and the 8.5-business as usual, which refer to an increase in solar radiation of $4.5 \mathrm{~W} / \mathrm{m}^{2}$ or $8.5 \mathrm{~W} / \mathrm{m}^{2}$ by 2100 , respectively.

To generate a future climate file, WeatherShift ${ }^{\circledR}$ calculates the offsets of each member of a set of climate projections. Using the warming percentile (WP) factor, the software indicates the percentage of available climate models that lead to an offset temperature lower than or equal to the one considered in the scenario.

For the case study in question two different climate scenarios were generated referring to the period 20262045 , both with a WP equal to $95 \%$ and an RCP of 4.5 and 8.5, respectively. These futures scenarios have been compared with the reference weather file (RW). Figure 1 shows the heating degree days (HDD) and the cooling hours $(\mathrm{CH})$ for the three scenarios, according to equations (2) and (3). The reference temperature for the calculation of the HDD has been set at $18{ }^{\circ} \mathrm{C}$, while in the evaluation of the $\mathrm{CH}$ it is equal to $26^{\circ} \mathrm{C}$.

$$
\begin{gathered}
H D D=\sum_{i=1,365}\left(T_{\text {ref }}-T_{\text {mean }}\right)=\sum_{i=1,365}\left(18-T_{\text {mean }}\right) \\
C H=\sum_{T_{\text {out }} \geq T_{\text {ref }}}\left(T_{\text {out }}-T_{\text {ref }}\right)=\sum_{T_{\text {out }} \geq 26\left(T_{\text {out }}-26\right)}
\end{gathered}
$$

Figures 2 and 3 show the trend of external temperatures in the three scenarios during the warmest days of summer (Figure 2) and the coldest ones in winter (Figure 3). If compared to the RW, the two climate scenarios evaluated with WeatherShift ${ }^{\circledR}$ have a very similar trend, with an average temperature increase of 
about $3{ }^{\circ} \mathrm{C}$ in the considered winter days and over $5{ }^{\circ} \mathrm{C}$ in the reported summer days.

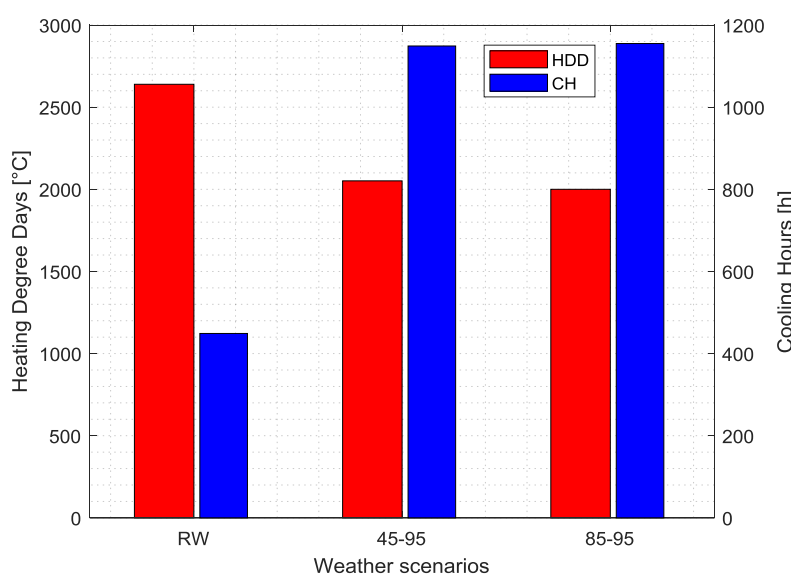

Fig. 1. Heating degree days and cooling hours.

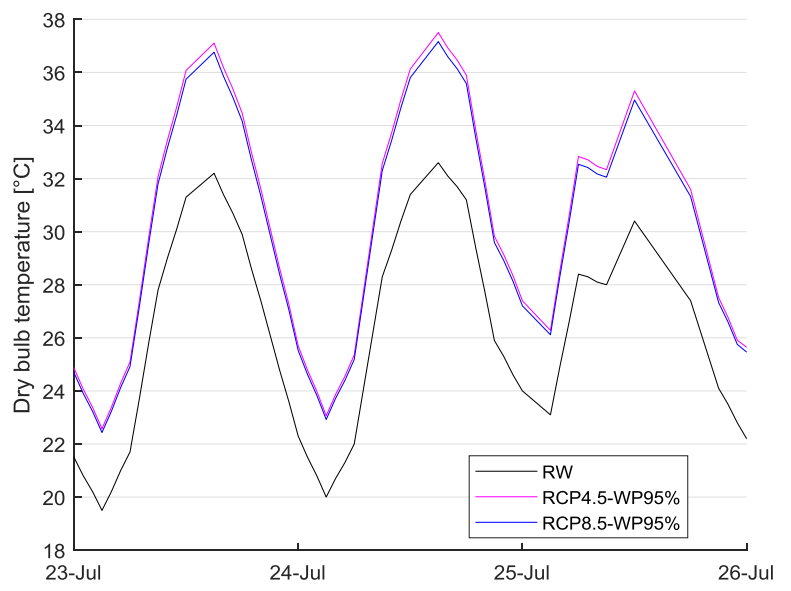

Fig. 2. Summer warmest days.

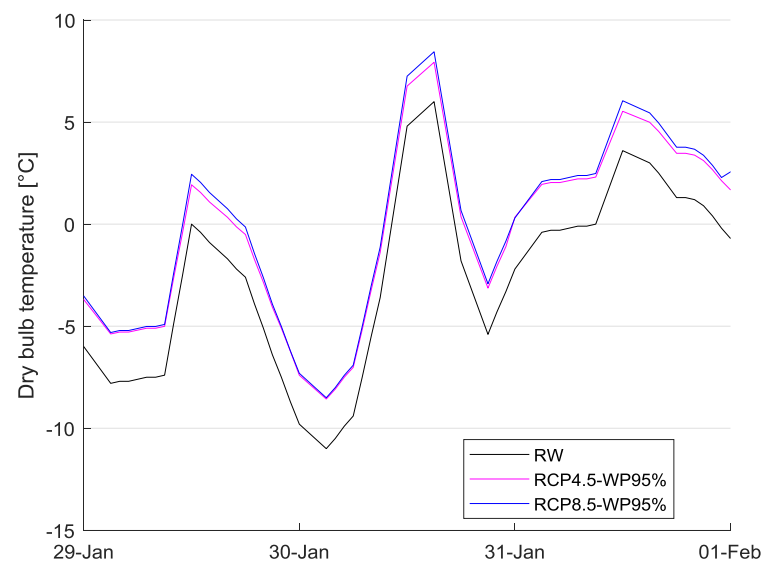

Fig. 3. Winter coldest days.

\section{Results and discussion}

The case study building was optimized in the three climate scenarios presented. The two future scenarios for the period 2026-2045 results led to similar results, which are quite different from the actual reference climate scenario (RW). The global cost, which represents the objective function to be minimized, has a value of $206.53 € / \mathrm{m}^{2}$ for the RW while it is lowered to 203.60 $€ / \mathrm{m}^{2}$ and $202.00 € / \mathrm{m}^{2}$ for the future scenarios respectively with RCP 4.5 and RCP 8.5. A similar behaviour is represented by the value of the primary energy related to the optimal solution, which also decreases in the future scenarios. The value of 88.53 $\mathrm{kWh} / \mathrm{m}^{2}$ of the reference weather goes down to 73.21 $\mathrm{kWh} / \mathrm{m}^{2}$ and $72.02 \mathrm{kWh} / \mathrm{m}^{2}$ respectively for the RCP 4.5 and RCP 8.5 scenarios.

Globally, the obtained results seem to describe a slight decrease in the overall cost of the case study building in future climate projections. On the other hand, from the primary energy point of view, the decrease is considerable.

The cost-optimal cloud as a function of the primary energy needs for all the simulations performed (about 1000 simulations for each climate scenario) is shown in Figure 4 . The optimal solutions have been highlighted by the larger dots in the figure. It can be noted how the optimal solutions in the 2026-2045 scenarios differ from the actual one $(\mathrm{RW})$, reporting lower values of both $\mathrm{C}_{\mathrm{G}}$ and $\mathrm{EP}_{\text {tot. }}$

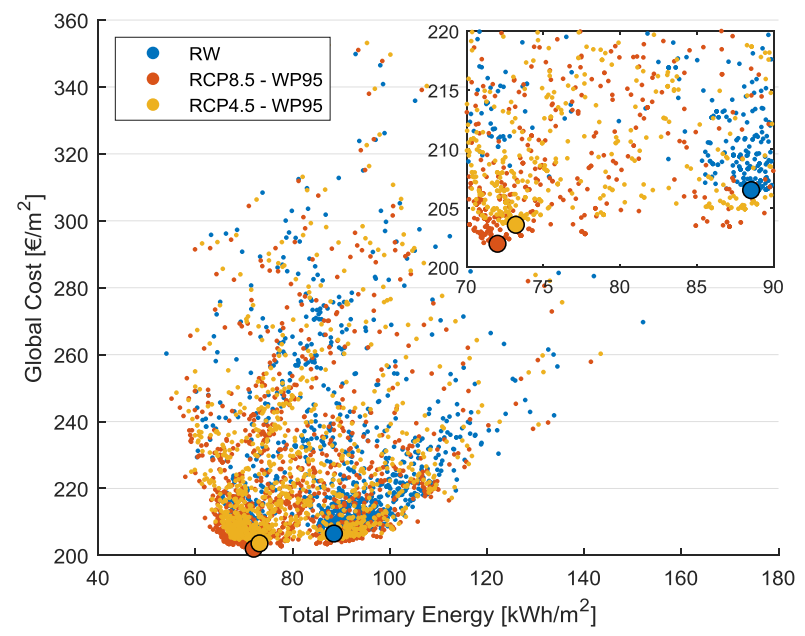

Fig. 4. Cost-optimal cloud for the three scenarios.

The sets of parameter values that correspond to the optimal solutions of each scenario are collected in Table 1. Next to the value of each parameter, its relative frequency in the neighbourhood of the optimal solution is reported. The optimum neighbourhood is a subset of points that was identified considering all the solutions that led to an objective function value not higher than $3.5 \%$ compared to the optimal value. The percentage of the relative frequency indicates how many times the value of the associated variable occurs within the neighbourhood. A high percentage value indicates the stability of the variable around the optimal solution, confirming a certain resilience of that parameter. Figure 5 shows the points enclosed in each neighbourhood of the three optimal solutions. It is interesting to note how the optimal solution relative to the RW falls within the neighbourhood of the optimal solutions for future 
scenarios. What clearly distinguishes the reference weather optimal solutions is the total consumption of primary energy, which is relatively higher compared to future scenarios.

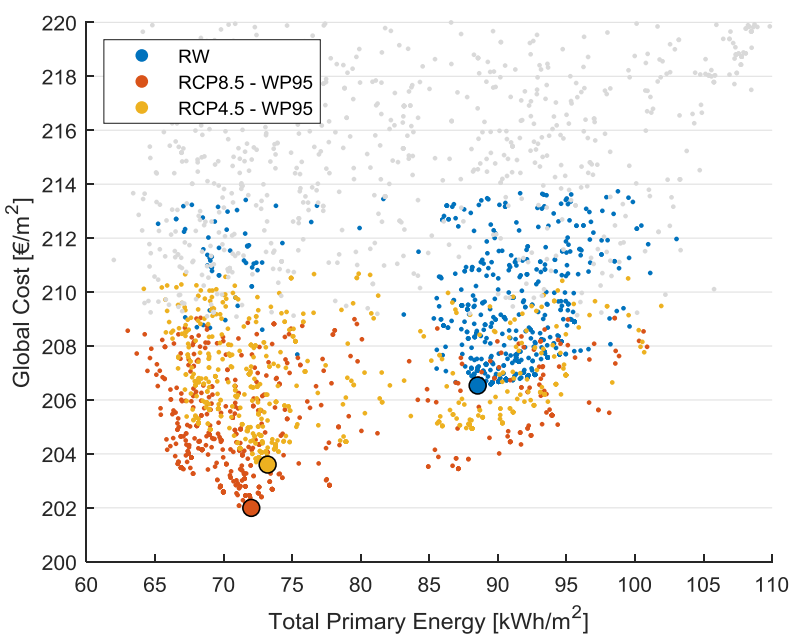

Fig. 5. Neighbourhood clouds.

The analysis of the results shows considerable stability for the parameters related to energy systems. All the best solutions have been identified with the same design choices in terms of power generation systems (primary and auxiliary), distribution terminals, thermal storage sizing and choice of photovoltaic panels. It can be also noticed how these plant parameters present a relative frequency in the neighbourhood always close to $100 \%$, indicating a strong stability within the optimum neighbourhood and a considerable resilience to the uncertain variation of climate scenarios.

On the other hand, by shifting the attention on the parameters characterizing the building envelope, different optimal solutions were found in the thermal resistances of the opaque walls, whose value decreases in the future climate scenarios. The climate change foreseen by the projections has therefore a greater influence on these parameters. This impact is further confirmed by the lower relative frequencies of the same parameters, which never exceed $90 \%$.

A different analysis can finally de done considering the impact of the energy produced through the PV panels, represented by the variable Perc-PV (percentage of the available roof area covered by photovoltaic panels). This parameter significantly undergoes climate change and its optimal value increases by 40 percentage points from the actual scenario to the future ones. This result suggests a future positive impact for photovoltaic installations that at the moment may seem over-sized. This outcome might be a consequence of the greater electricity consumption in the future, especially due to an increase in the energy demand for the air conditioning of buildings, as had already been identified in Figure 1, where the cooling hours for future scenarios showed values significantly higher than the current ones.Table 1 also contains the energy need for heating $\left(\mathrm{QH}_{\mathrm{H}, \mathrm{nd}}\right)$ and cooling ( $\left.\mathrm{Q}_{\mathrm{C}, \mathrm{nd}}\right)$ of the building corresponding to the optimal design solutions in all scenarios. These values indicate the impact that the climate projections will have on seasonal consumption of optimally designed buildings.

Table 1. Optimal set of variables values and relative frequency.

\begin{tabular}{|c|c|c|c|c|c|c|}
\hline Scenario & \multicolumn{2}{|c|}{ OPT_RW } & \multicolumn{2}{|c|}{ OPT_8.5-95 } & \multicolumn{2}{|c|}{ OPT_4.5-95 } \\
\hline Parameter & $\begin{array}{l}\text { Variable } \\
\text { value }\end{array}$ & $\begin{array}{l}\text { Relative } \\
\text { Frequency } \\
\text { (neighbour } \\
\text { hood) }\end{array}$ & $\begin{array}{l}\text { Variable } \\
\text { value }\end{array}$ & $\begin{array}{l}\text { Relative } \\
\text { Frequency } \\
\text { (neighbou } \\
\text { rhood) }\end{array}$ & Variable & \begin{tabular}{|l|} 
Relativ \\
e \\
Frequen \\
cy \\
(neighb \\
ourhoo \\
d) \\
\end{tabular} \\
\hline $\begin{array}{l}\text { ResO-N } \\
{\left[\left(\mathrm{m}^{2} \mathrm{~K}\right) / \mathrm{W}\right]}\end{array}$ & 1.7165 & $54 \%$ & 1.1455 & $71 \%$ & 1.1455 & $63 \%$ \\
\hline $\begin{array}{l}\text { ResO-EOS } \\
{\left[\left(\mathrm{m}^{2} \mathrm{~K}\right) / \mathrm{W}\right]}\end{array}$ & 1.7165 & $44 \%$ & 1.1455 & $71 \%$ & 1.1455 & $83 \%$ \\
\hline $\begin{array}{l}\operatorname{Res} 2 \\
{\left[\left(\mathrm{~m}^{2} \mathrm{~K}\right) / \mathrm{W}\right]}\end{array}$ & 0 & $89 \%$ & 0 & $88 \%$ & 0 & $85 \%$ \\
\hline $\begin{array}{l}\text { ResR } \\
{\left[\left(\mathrm{m}^{2} \mathrm{~K}\right) / \mathrm{W}\right]}\end{array}$ & 0.6095 & $30 \%$ & 0 & $89 \%$ & 0 & $87 \%$ \\
\hline WTS & $\begin{array}{r}\text { Double } \\
\text { glazing, } \\
\text { low-E, } \\
\text { with } \\
\text { Argon }\end{array}$ & 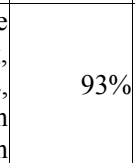 & $\begin{array}{r}\text { Double } \\
\text { glazing, } \\
\text { low-E, } \\
\text { with } \\
\text { Argon }\end{array}$ & $92 \%$ & $\begin{array}{r}\text { Double } \\
\text { glazing, } \\
\text { low-E, } \\
\text { with } \\
\text { Argon }\end{array}$ & $92 \%$ \\
\hline WTN & $\begin{array}{r}\text { Double } \\
\text { glazing, } \\
\text { low-E, } \\
\text { with } \\
\text { Argon }\end{array}$ & 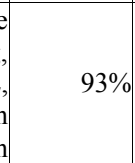 & $\begin{array}{r}\text { Double } \\
\text { glazing, } \\
\text { low-E, } \\
\text { with } \\
\text { Argon }\end{array}$ & $92 \%$ & $\begin{array}{r}\text { Double } \\
\text { glazing, } \\
\text { low-E, } \\
\text { with } \\
\text { Argon }\end{array}$ & $92 \%$ \\
\hline WTEW & $\begin{array}{r}\text { Double } \\
\text { glazing, } \\
\text { low-E, } \\
\text { with } \\
\text { Argon }\end{array}$ & 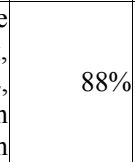 & $\begin{array}{r}\text { Double } \\
\text { glazing, } \\
\text { low-E, } \\
\text { with } \\
\text { Argon }\end{array}$ & $78 \%$ & $\begin{array}{r}\text { Double } \\
\text { glazing, } \\
\text { low-E, } \\
\text { with } \\
\text { Argon }\end{array}$ & $69 \%$ \\
\hline WFactor [-] & 0.8 & $98 \%$ & 0.8 & $98 \%$ & 0.8 & $97 \%$ \\
\hline T-Gen & $\begin{array}{r}\text { Heat } \\
\text { pump }\end{array}$ & $100 \%$ & $\begin{array}{r}\text { Heat } \\
\text { pump }\end{array}$ & $99 \%$ & $\begin{array}{r}\text { Heat } \\
\text { pump }\end{array}$ & $100 \%$ \\
\hline T-Ter & Fancoils & $100 \%$ & Fancoils & $100 \%$ & Fancoils & $100 \%$ \\
\hline T-PV & $\begin{array}{r}\text { Polycrys } \\
\text { talline }\end{array}$ & $99 \%$ & $\begin{array}{r}\text { Polycrys } \\
\text { talline }\end{array}$ & $100 \%$ & $\begin{array}{r}\text { Polycryst } \\
\text { alline }\end{array}$ & $100 \%$ \\
\hline $\begin{array}{l}\text { Dim-WS } \\
{\left[1 / \mathrm{m}^{2}\right]}\end{array}$ & 100 & $97 \%$ & 100 & $97 \%$ & 100 & $97 \%$ \\
\hline T-Aux & Gas & $100 \%$ & Gas & $100 \%$ & Gas & $100 \%$ \\
\hline $\begin{array}{l}\text { Perc-PV } \\
{[\%]}\end{array}$ & 36 & $59 \%$ & 76 & $51 \%$ & 76 & $47 \%$ \\
\hline $\begin{array}{l}\text { Perc-TH } \\
{[\%]}\end{array}$ & 11 & $91 \%$ & 11 & $89 \%$ & 11 & $89 \%$ \\
\hline $\mathrm{C}_{\mathrm{G}}\left[€ / \mathrm{m}^{2}\right]$ & & 06.53 & & 2.00 & 203. & .60 \\
\hline \begin{tabular}{|l|} 
EPtot \\
{$\left[\mathrm{kWhEp} / \mathrm{m}^{2}\right]$} \\
\end{tabular} & & 8.52 & & 2.02 & 73.2 & \\
\hline \begin{tabular}{|l|} 
EPnren \\
{$\left[\mathrm{kWhEp} / \mathrm{m}^{2}\right]$}
\end{tabular} & & 8.10 & & 1.02 & 61.7 & \\
\hline $\begin{array}{l}\text { QH,nd } \\
{\left[\mathrm{kWh} / \mathrm{m}^{2}\right]}\end{array}$ & & 2.79 & & 8.41 & 19.5 & \\
\hline $\begin{array}{l}\text { QC,nd } \\
{\left[\mathrm{kWh} / \mathrm{m}^{2}\right]}\end{array}$ & & 9.34 & & 9.69 & 19.3 & \\
\hline
\end{tabular}

The winter heating demand will tend to decrease, while the energy spent for summer air conditioning will double if the scenarios of 2026-2045 are considered. This shift in energy requirements is also highlighted in Figure 6, which depicts the trends described above for the simulated scenarios. The future projections of the energy need in buildings reflect the trends already analysed in Figure 1 for the heating degree days and the cooling hours. Following the results obtained, it is clear that summer air conditioning will engage more and more 
interest in the design of energy efficient future HVAC systems [22-23].

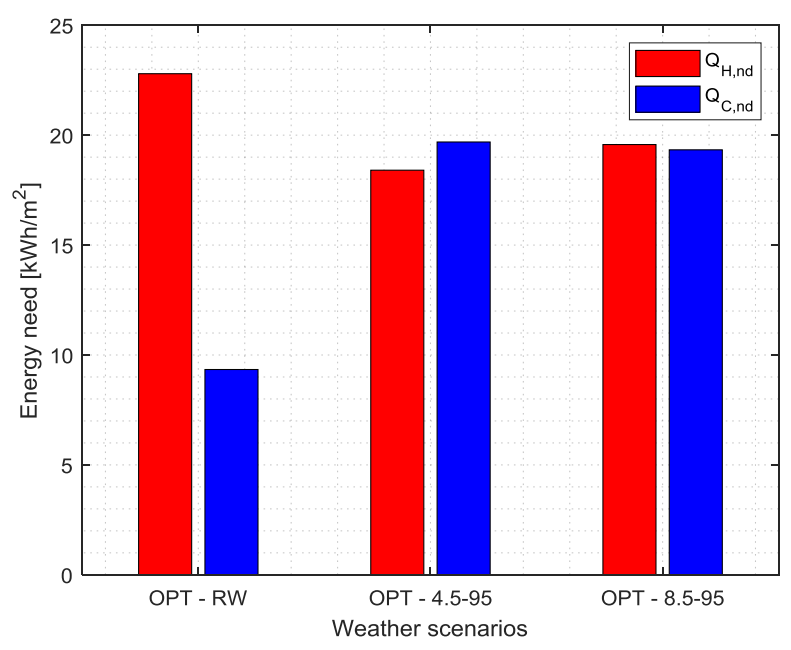

Fig. 6. Energy needs actual and future trends for optimal solutions.

\section{Conclusion}

The cost-optimization of a residential complex located in Milan, Italy, was carried out using future climate scenarios for the period 2026-2045 and comparing the results obtained with the current weather conditions.

The new EDeSSOpt optimization methodology has been applied to the case study, integrating in the same optimization algorithm both the energy demand and supply characteristics that define the building.

The purpose of this study was a resilience analysis of both envelope and systems parameters of the case study. The results obtained have shown how systems that involve heat pumps integrated with an auxiliary gas generator and fan coils as distribution terminals turn out to be an optimal solution both in terms of cost and in terms of resilience to possible climatic variations. As expected, the effects of climate projections could lead to a reduction in winter energy need for heating, whereas the energy need for summer air conditioning will tend to increase. For this reason, the analysis carried out shows how the thermal resistances of building envelope components resulting in the cost-optimal solution decrease in future scenarios.

Future developments of the study presented in this paper can be conducted considering future possible climate scenarios or implementing new variables in the optimization algorithm. A more detailed application of the methodology proposed can ultimately enable targeted design decisions to be made, having a significant impact in the cost-optimization of future projects.

We acknowledge Ben Brannon for providing the data from the WeatherShiftTM tool that were used in this work.

This work has been done within the Starting Grant 2016 project funded by the Compagnia di San Paolo at the Politecnico di Torino.

\section{References}

1. D. D'agostino, B. Cuniberti, P. Bertoldi, Energy Build. 153, 72-86 (2017)

2. European Energy Agency, Indic. Assess. | Data maps. (2015)

3. EU, Directive 2010/31/EU of the European Parliament and of the Council of 19 May 2010 on the energy performance of buildings (2010)

4. EU, Directive 2018/844/EU of the European Parliament and of the Council of 30 May 2018. (2018)

5. S. Longo, F. Montana, E. Riva, Sust. Cities Soc. In press (2018)

6. M. Ferrara, V. Monetti, E. Fabrizio, Energies 11 (2018)

7. R. D. Bingham, M. Angelin-Chaab, M. A. Rosen, Ren. En. 132, 1088-1103 (2018)

8. C. Carpino, R. Bruno, N. Arcuri, En. Build. 174, 642-656 (2018)

9. S. Hallegatte, Glob. Env. Change 19, 240-247 (2009)

10. J. Kočí, V. Kočí, J. Maděra, R. Črný, Ren. Sust. En. Rev. 100, 22-32 (2019)

11. L. Wang, X. Liu, H. Brown, En. Build. 157, 218226 (2017)

12. IPCC, 2014: Climate Change 2014: Synthesis Report. Contribution of Working Groups I, II and III to the Fifth Assessment Report of the Intergovernmental Panel on Climate Change [Core Writing Team, R.K. Pachauri and L.A. Meyer (eds.)]. IPCC, Geneva, Switzerland, $151 \mathrm{pp}$.

13. M.Ferrara, E.Fabrizio, Energy Procedia 122, $877-$ 882 (2017).

14. M. Ferrara, A. Rolfo, F. Prunotto, E. Fabrizio. Appl Energy, in press (2018).

DOI:10.1016/j.apenergy.2018.12.043

15. M. Ferrara, F. Dabbene, E. Fabrizio, Proceedings of Building Simulation Conference BS2017 (2017).

16. EN 15459: Energy performance of buildings, Economic Evaluation Procedure for energy Systems in Buildings (2007)

17. UNI TS 11300-5: Calcolo dell'energia primaria e della quota di energia da fonti rinnovabili (2016)

18. M. Hamdy, A. Hasan, K. Siren, Energy Build. 56, 189-203. (2013)

19. WeatherShift ${ }^{\circledR}$ tool, http://www.weather-shift.com

20. S.E. Belcher, J.N. Hacker, D.S. Powell, Build Serv Eng Res Technol. 61, 49-62 (2005)

21. L. Wang, X., Liu, H., Brown, Energy Build. 157, 218-226 (2017).

22. E. Fabrizio, S.P. Corgnati, F. Causone, M. Filippi, HVAC and R Research 18, 692-708 (2012).

23. M. Ferrara, E. Fabrizio, J. Virgone, M. Filippi, Automation in Construction 70, 109-127 (2016). 


\section{Appendix A. Optimization variables and cost functions}

Table A.1. Envelope variables and related cost functions

\begin{tabular}{|c|c|c|c|c|c|c|}
\hline Parameter & Description & Unit & Min & Max & Step & $\begin{array}{c}\text { Cost function } \\
{\left[€ / \mathrm{m}^{2}\right]}\end{array}$ \\
\hline $\begin{array}{c}\text { ResO-N } \\
\text { ResO- } \\
\text { EOS } \\
\text { Res2 }\end{array}$ & $\begin{array}{c}\text { Thermal } \\
\text { resistance of } \\
\text { opaque } \\
\text { components }\end{array}$ & $\frac{\mathrm{m}^{2} \mathrm{~K}}{\mathrm{~W}}$ & 1,143 & 5,714 & $2 \mathrm{~cm}$ & $4,97 *$ ResO+3,36 \\
\hline ResR & $\begin{array}{c}\text { Thermal } \\
\text { resistance of } \\
\text { roof }\end{array}$ & $\frac{\mathrm{m}^{2} \mathrm{~K}}{\mathrm{~W}}$ & 1,212 & 6,061 & $2 \mathrm{~cm}$ & $5,775^{*}$ ResR+2,6 \\
\hline $\begin{array}{c}\text { WTS } \\
\text { WTN } \\
\text { WTEW }\end{array}$ & $\begin{array}{c}\text { Window } \\
\text { type }\end{array}$ & {$[-]$} & 1 & 4 & 1 & See table A.2 \\
\hline
\end{tabular}

Table A.2. Windows types and related cost functions

\begin{tabular}{|c|c|c|c|c|c|}
\hline $\begin{array}{c}\text { Window } \\
\text { type }\end{array}$ & Description & Composition & $\left.\begin{array}{c}\mathrm{UW} \\
{\left[\mathrm{W} /\left(\mathrm{m}^{2} \mathrm{~K}\right)\right.}\end{array}\right]$ & $\begin{array}{c}\mathrm{g}- \\
\text { value }\end{array}$ & $\begin{array}{c}\text { Cost } \\
{\left[€ / \mathrm{m}^{2}\right]}\end{array}$ \\
\hline 1 & $\begin{array}{c}\text { Double glazing, } \\
\text { w/o Argon }\end{array}$ & $4 / 16 / 4$ & 2,83 & 0,755 & 166,6 \\
\hline 2 & $\begin{array}{c}\text { Double glazing, } \\
\text { low-E, with Argon }\end{array}$ & $4 / 15 / 4$ & 1,1 & 0,609 & 179,85 \\
\hline 3 & $\begin{array}{c}\text { Double glazing, } \\
\text { low-E and solar } \\
\text { control, with Argon }\end{array}$ & $6 / 16 / 6$ & 1,29 & 0,333 & 220,81 \\
\hline 4 & $\begin{array}{c}\text { Triple glazing, low- } \\
\text { E and solar control, } \\
\text { with Argon }\end{array}$ & $6 / 12 / 4 / 12 / 4$ & 0,7 & 0,294 & 266,41 \\
\hline 5 & $\begin{array}{c}\text { Triple glazing, low- } \\
\text { E, with Argon }\end{array}$ & $4 / 16 / 4 / 16 / 4$ & 0,7 & 0,501 & 217,19 \\
\hline
\end{tabular}

Table A.3. Technical components and related cost functions

\begin{tabular}{|c|c|c|}
\hline Technical component & Design variable & Cost $[€]$ \\
\hline Traditional boiler & Thermal power $\mathrm{P}_{\text {th }}$ & $17.283 * \mathrm{P}_{\mathrm{th}}+1282.2$ \\
\hline Condensing boiler & Thermal power $\mathrm{P}_{\mathrm{th}}$ & $43.515^{*} \mathrm{P}_{\mathrm{th}}+2634$ \\
\hline Air cooled chiller & Cooling power $\mathrm{P}_{\mathrm{co}}$ & $139.22 * \mathrm{P}_{\mathrm{th}}+3014.2$ \\
\hline Water cooled chiller & Cooling power $\mathrm{P}_{\mathrm{co}}$ & $73.29 \boldsymbol{F}^{*} \mathrm{P}_{\mathrm{th}}+4239.3$ \\
\hline Heat pump & Cooling power $\mathrm{P}_{\mathrm{co}}$ & $579.21 * \mathrm{P}_{\mathrm{f}}^{0.6535}$ \\
\hline Thermal storage $(1 \mathrm{HX})$ & Storage volume $\mathrm{V}_{\mathrm{ts}}$ & $1.18 * \mathrm{~V}_{\mathrm{ts}}+1266.7$ \\
\hline Thermal storage $(2 \mathrm{HX})$ & Storage volume $\mathrm{V}_{\mathrm{ts}}$ & $1.76 * \mathrm{~V}_{\mathrm{ts}}+1579.8$ \\
\hline
\end{tabular}

